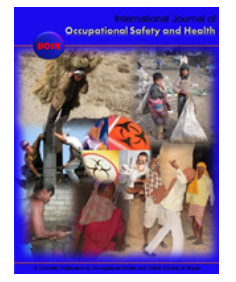

Available Online at http://nepjol.info/index.php/IJOSH

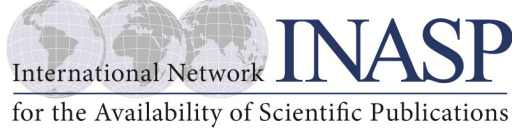

International Journal of Occupational Safety and Health, Vol 2. No 2 (2012) 1 - 2

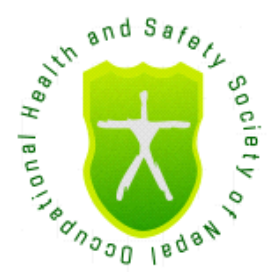

Editorial

\title{
Occupational Ergonomics in Industrially Developing Countries.
}

\author{
Somnath Gangopadhyay \\ Occupational Ergonomics Laboratory, Department of Physiology \\ University of Calcutta
}

Occupational Ergonomics is a definite and a special domain of ergonomics which deals with occupational health of workers in various working fields. It has a great impact on the society and socioeconomic status of workers. In other sense, socioeconomic status of workers will solely depend on their health and productivity. It is obvious that better work station increases the health status of workers. But implementation of the same is a big question for economically poor countries.

Unfortunately, in India, statistics on occupational diseases and injuries is not maintained regularly. From the report of Leigh et al. (1999) annual occupational disease in India is found to be $9,24,700$ to $19,02,300$ and number of deaths are found to be $1,21,000$. It is further observed that major occupational diseases in India are silicosis, musculoskeletal injuries, coal workers' pneumoconiosis, chronic obstructive lung diseases, asbestosis, byssinosis, pesticide poisoning and noise induced hearing loss (Saiyed and Tiwari 2004). A similar picture has emerged from other developing countries as well.

Moreover, in developing countries like India, a large number of workers, more than $50 \%$ of the total working population, are directly engaged in the informal sectors. During work, this population are compelled to violate the natural laws of work. They bound to work in a low wage condition with maximum amount of physical effort and minimum amount of safety.

These observations have opened the door for more researches on Occupational health and Ergonomics in quest of health protection for vulnerable workers.
The importance of occupational ergonomics encourages IJOSH to release a special issue on Occupational Ergonomics to accumulate the current researches in this vibrant field of work.

In 2011, the Department of Physiology, University of Calcutta had organized an International Conference on "Molecules to Systems Physiology" (ICMSP100) from 21.09.11 to 23.09.11. as a part of the centenary celebration of the Department. The three day long conference ICMSP100 spread over different locations within the heritage campus of University of Calcutta, had 360 participants from different regions of India and also abroad.

About 158 papers were presented in different scientific sessions on Ergonomics and Occupational Physiology, Environmental Physiology, Sports Physiology, Biochemistry and Biophysics, Cancer Biology, Clinical Physiology, Community Nutrition and Biochemical Nutrition, Endocrinology and Reproductive Physiology, Modern Trends in Toxicology, Molecular Physiology, Nano science in Physiology, Neurophysiology and Neurodegenerative Diseases, Stress Physiology, Cell Signalling.

Among these 158 papers, 50 papers were submitted exclusively in the session of Ergonomics and Occupational Physiology. After the conference, discussion with executive editor of IJOSH, it was decided to release a special issue on Occupational Ergonomics. A preliminary selection process was done and authors were intimated to resubmit their articles after formatting as IJOSH guidelines. Submitted and formatted articles were passed through proper review process of the journal and among the initially selected ones, only 7 articles are accepted for publication.

These 7 articles depict the working lives of underground coalminers, china clay mine workers, loader and dozer operators of open cast mines, cycle rickshaw pullers, aluminium casting workers, healthcare unit personnel and brick kiln workers. 
In the coalminers' study, it was found that the maximum pain was felt at lower back. According to the study, the repetitive operations of moving heavy substances and stooping postures were the risk factors for the development of work related musculoskeletal disorders in neck, shoulder and lower back of these workers.

A descriptive study was done on china clay mine workers. Researchers observed that about $79 \%$ of total population was suffering from different grades of COPD which might be due to exposure of china clay dust in the work place.

Another interesting study was one on loader and dozer operators of open cast mines. Continuous change of movement in forward and reverse direction and rash driving by these operators were found to be contributory factors for increased vibration intensity among them. From the result of the study, vibration control measures were suggested.

In the article on Physiological changes in cycle rickshaw pullers after strenuous exercise, work stress of rickshaw pullers were estimated through the average working heart rate (AWHR), peak working heart rate (PWHR), maximal heart rate (HRmax) and energy expenditure (EE) of rickshaw pullers. In the experimental design, eleven control subjects were allowed to work in a cycle ergometer in the laboratory. The AWHR, PWHR and EE values of rickshaw pullers showed the workload as 'heavy' to 'very heavy' category.

In another physiological study on aluminium casting workers, working heart rate, net cardiac cost, relative cardiac cost and recovery heart rates were determined. The study revealed the predominant static nature of the tasks. Overall strain of the job appeared moderate in nature but recovery patterns were inadequate for majority of the workers.

In the study on healthcare unit personnel where the study was done on 150 staff nurses and 175 attendants working in three government hospitals in West Bengal. The researchers tried to evaluate their perception of workload in different shifts and to develop better management protocols through the concept of macro ergonomics. Perceived exertion rating of healthcare unit personnel at night shift was found more than other shifts but surprisingly physiological responses did not reflect the same.

In the last article on brick kiln workers, pain categorization was done by Pain Detect Tool. Results showed that pain/discomfort was mainly at the low back. $72 \%$ of workers had a pain of $>20$ in the pain scale of the pain detect tool and $80 \%$ of workers were not satisfied with treatments with analgesics/antipyretics. Authors concluded the presence of the neuropathic pain among them.

\section{References:}

Leigh J, Macaskill P, Kuosma E, Mandryk J (1999) Global burden of disease and injuries due to occupational factors. Epidemiol 10, 626-31.

Habibullah N Saiyed and Rajnarayan R Tiwari (2004) Occupational Health Research in India, Industrial Health, 42, 141-148 